\title{
ENTREVISTA COM O PROF. DR. JOSE CAMILO DOS SANTOS FILHO
}

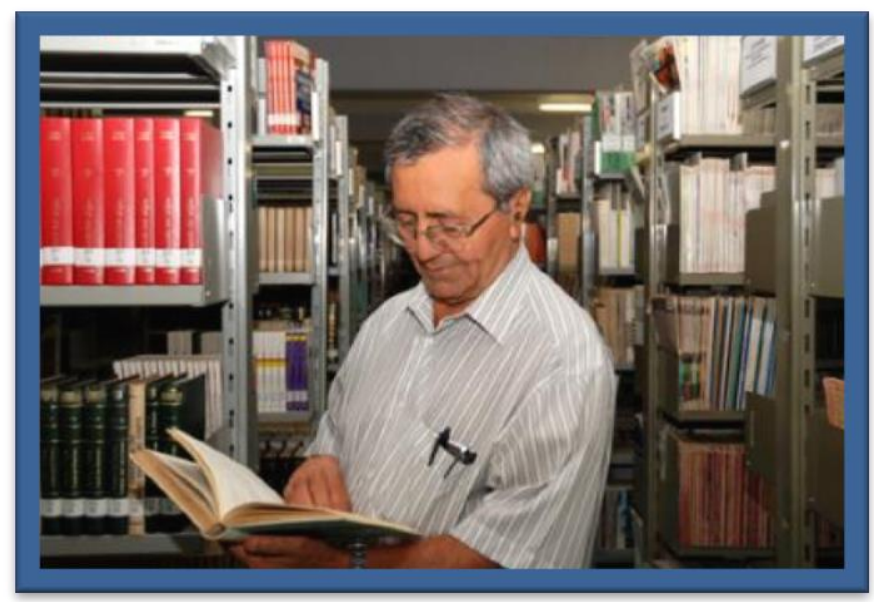

Possui graduação em Curso de Pedagogia pela Universidade Católica de Pernambuco (1962), graduação em Filosofia pela Faculdade Salesiana de Filosofia, Ciências e Letras (1960), Mestrado em Educação (Master of Science in Education), mestrado em Administração Pública (M.P.A.) e doutorado em Educação (Ph.D. in education) pela University of Southern California (1971-1974) e pós-doutorado pela University of California at Los Angeles (UCLA). Atualmente é Doutor Pesquisador Colaborador na Faculdade de Educação da UNICAMP, atuando como coordenador do GEPES - Grupo de Estudos e Pesquisas em Educação Superior, pesquisador fundador do GIEPES - Grupo Internacional de Estudos e Pesquiass em Educação Superior. É editor chefe da Revista Internacional de Educação Superior - RIESup, sediada no site da FE da Unicamp. Email: jcamilosantos@gmail.com

Professor Camilo, agradecemos por acolher este convite, destinando seu tempo para esta Entrevista.

\section{1) Fale-nos um pouco de sua trajetória na Unicamp, como iniciou suas atividades.}

Na PUC/RJ tinha começado o mestrado em educação em 1969 e iniciado a lecionar em 1970. Com uma bolsa de estudo, parti para os Estados Unidos para fazer o doutorado em educação na University of Southern California (USC, Los Angeles). Na USC, num programa articulado e integrado visando o doutorado, terminei o mestrado em educação (major em currículo escolar) em 1972, o mestrado em administração pública em 1973 e o Ph. em educação em1974. Fiz o doutorado no Departamento de Educação Superior da School of Education com o major em currículo da educação superior.

Após o término do doutorado no final de 1974, fui recontratado pela PUC do Rio de Janeiro que já tinha um programa de mestrado em educação há mais de dez anos e um programa de doutorado em educação do qual participei para sua criação em 1976, 


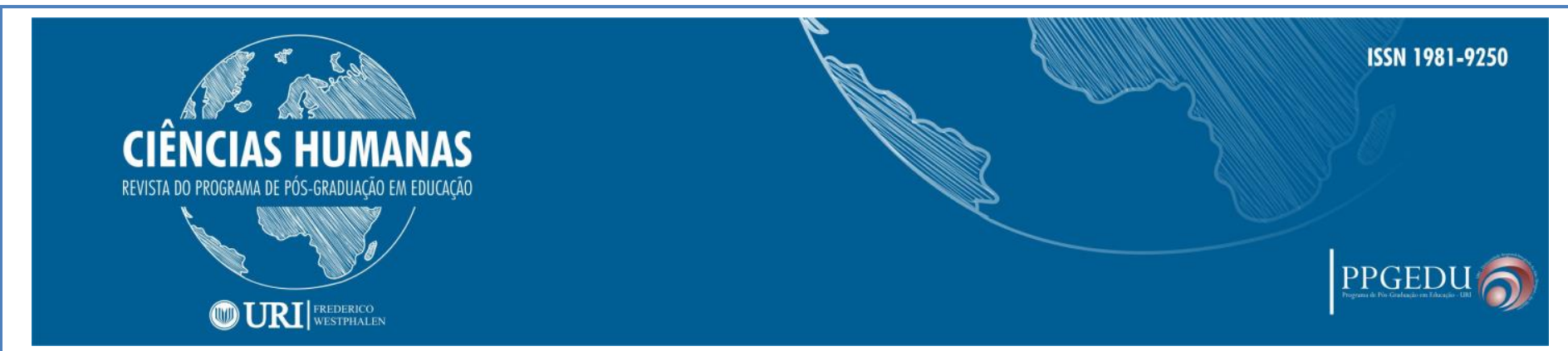

sendo este o primeiro doutorado em educação criado em universidade brasileira. Tinha o compromisso de trabalhar na PUC por pelos menos dois anos. Fiquei dois anos e meio. No começo do segundo semestre de 1977 fui convidado pela Unicamp para trabalhar na Faculdade de Educação. Na mesma época tinha recebido convite para trabalhar num projeto do Banco Mundial no MEC em Brasília, na Universidade Federal do Espírito Santo, na Universidade Federal de São Carlos e a continuar na PUC/RJ. Vim para a Unicamp sem contrato assinado e passei os três primeiros meses sem receber um centavo de salário da universidade, pois a assinatura de meu contrato só saiu no quarto mês. Meus colegas da PUC do Rio me taxaram de "louco". Em termos financeiros, a melhor escolha teria sido o emprego no programa do Banco Mundial. Em termos de segurança no emprego, uma das duas universidades federais teria sido, na circunstância, a melhor opção. Na época, não estava preocupado, nem com segurança no emprego nem com vantagens financeiras num emprego de técnico do MEC [era relativamente jovem!], mas com a vida acadêmica universitária que a UNICAMP, com sua mística e imagem externa, já parecia prometer. Via na jovem UNICAMP uma réplica da Universidade Stanford ou da Universidade de Chicago da última década do século XIX quando foram fundadas. Olhando para trás, acho que fiz a escolha certa. Hoje a UNICAMP se classifica entre as duas melhores universidades do país.

Em função de minha formação pós-graduada, vim para a Unicamp para lecionar “currículos e programas” quando Zeferino Vaz, seu fundador, ainda era seu reitor. Minha trajetória acadêmica na Faculdade de Educação da Unicamp começou já no segundo semestre de 1977 com a docência no curso de Pedagogia e no mestrado em educação que tinha sido aberto apenas dois anos antes e não tinha sequer uma dissertação defendida. No ano seguinte comecei a fazer parte da comissão de pósgraduação e em março de 1978, junto com o coordenador do programa, Prof. Dr. Newton Aquiles von Zuben, participei do encontro promovido pela Capes para a criação e organização da ANPED (Associação Nacional de Pós-graduação em Educação), realizado na Fundação Getúlio Vargas, do Rio de Janeiro. Neste evento, tornei-me sócio-fundador da Anped junto com os colegas que participaram do evento. 


\section{CIÊNCIAS HUMANAS}

REVISTA DO PROGRAMA DE PÓS-GRADUAC̄̄o EM EDUCACĞ̄o

\section{(1) URI|}

Em 1979 participei do grupo, coordenado pelo Prof. Dr. Moacir Gadotti, que criou a Revista Educação e Sociedade, inicialmente pensada como revista da Faculdade de Educação, mas devido aos entraves burocráticos internos à universidade para sua edição, seu editor Gadotti, propôs a fundação de um Centro de Estudos Educação e Sociedade (CEDES), independente da Faculdade e da Unicamp para administrar a revista a partir de seu segundo número, promover eventos e realizar pesquisas educacionais. Fui membro do grupo fundador do CEDES e membro do primeiro conselho editorial da Revista Educação e Sociedade.

Como a Faculdade de Educação ficou sem sua revista, em 1984 e 1985 fui membro da segunda comissão de criação de nova Revista da Faculdade, mas o projeto não vingou por falta de interesse da Editora da Unicamp e por desacordos internos na Faculdade. Por isso, de novo em 1988 foi constituída uma terceira comissão, da qual participei, para elaborar o projeto da revista da Faculdade, finalmente fundada em 1990 com o nome de Pro-Posições a ser editada pela Cortez Editora. Fui escolhido pelos membros da primeira comissão editorial da revista para ser seu editor e meu nome foi chancelado pelo diretor da Faculdade na época, o Prof. Dr. José Dias Sobrinho. Fui editor da revista por oito anos, num período que chamaria de heroico para manter uma revista funcionando, apesar das precariedades administrativas e da ausência de suporte financeiro de agências de fomento à pesquisa, como o CNPp e a FAPESP. Mesmo nesse contexto, em 1991 consegui indexar a revista em quatro indexadores, um nacional, dois estrangeiros e um da UNESCO, quando poucas revistas brasileiras estavam indexadas. Com a revista Pro-Posições fizemos permutas com centenas de periódicos estrangeiros.

Além dessas iniciativas editoriais, participei na criação de outras revistas educacionais em outras universidades ou instituições de educação superior do país. Todo esse esforço e envolvimento na edição de periódicos aconteceu por entender que a divulgação das pesquisas e estudos são um elo essencial e importante do processo da pesquisa nacional, sem o qual seus benefícios ficam restritos ou mesmo nulos.

Outra atividade vinculada à pesquisa e que considero relevante em minha trajetória na Unicamp foi a coordenação da Biblioteca da Faculdade de Educação por doze anos. Nesse período fiz todo o esforço para ampliar o acervo de livros e periódicos 


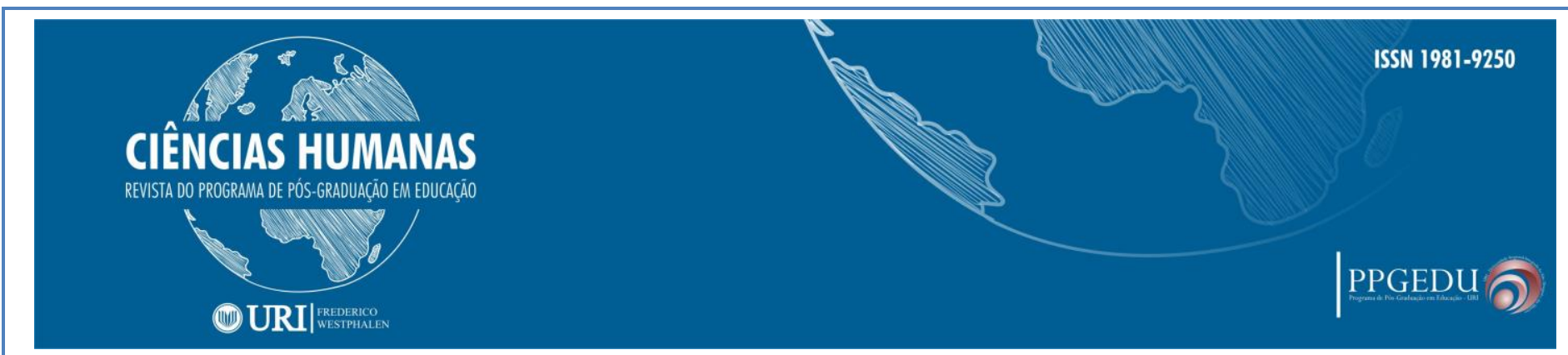

da Biblioteca da Faculdade no que fui relativamente bem-sucedido. Quando deixei a coordenação, a biblioteca mantinha a assinatura de cerca de seiscentos títulos estrangeiros, além das melhores revistas educacionais do país. Durante minha formação de educador e pesquisador aprendi que as bibliotecas universitárias e pessoais são um fator essencial de suporte à docência e à pesquisa atualizada. Por isso, nas universidades onde trabalhei fui um colaborador ativo das bibliotecas e um frequentador assíduo de várias bibliotecas ao longo de minha formação e de minha carreira de docentepesquisador.

Um marco importante em minha formação como pesquisador foi a experiência do pós-doutorado na UCLA em 1982-1983, onde e quando participei das atividades de dois grupos de pesquisa sobre educação superior. O primeiro, coordenado pelo Prof. Dr. Burton Clark, era composto por professores-pesquisadores e pós-doutorandos dos Estados Unidos e de vários outros países. Das rodadas de seminários discutindo textos dos participantes resultava a publicação de um livro coletivo sobre a temática selecionada. Esta experiência de trabalho de grupo de pesquisadores foi muito enriquecedora. $\mathrm{O}$ segundo grupo, coordenado pelo pesquisador nacionalmente conhecido, Alexander Astin, fundador e diretor do Higher Education Research Institute (HERI), da UCLA, era formado por docentes e pós-graduandos e pesquisava problemas da educação superior americana. Enquanto o primeiro grupo realizava mais pesquisas qualitativas e comparativas, o segundo fazia grandes pesquisas quantitativas. Essas foram duas experiências complementares de abordagem de pesquisa e de trabalho de pesquisa em grupo.

De retorno do pós-doutorado para a Unicamp, trouxe a vivência de grupos de pesquisa na área da educação superior. Na Faculdade de Educação, coordenei o grupo de pesquisa sobre "novas propostas alternativas de administração da educação" com 10 subprojetos, no período de 1986 a 1989. Desses subprojetos, oito resultaram em dissertações de mestrado em educação e vários dos que concluíram o mestrado ingressaram no doutorado. No período de 1994 a 1996, coordenei o projeto de pesquisa “gestão democrática da escola pública; obstáculos, possibilidades e implicações”, do 


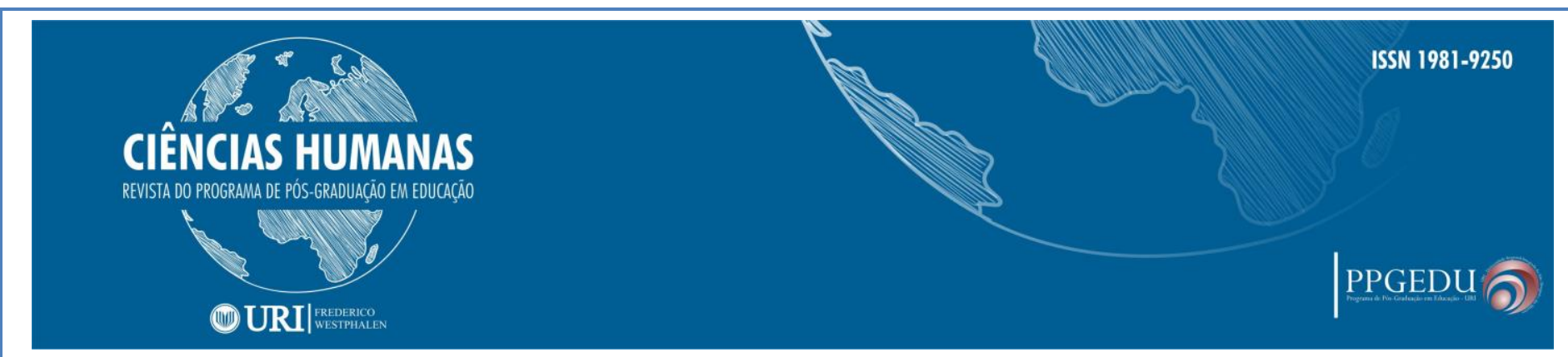

qual participaram colegas de departamento e doutorandos que participaram do projeto anterior como mestrandos.

Em 1987, elaborei projeto de criação de um grupo de pesquisa em educação superior (o nome estava para ser escolhido entre núcleo, centro, grupo; daí as siglas NEPES, CEPES, GEPES) e, finalmente, prevaleceu o nome de grupo que começou a funcionar informalmente já a partir desse ano promovendo seminários quinzenais com mestrandos e doutorandos. Depois de aprovado formalmente pela Congregação da Faculdade em 1992, o GEPES sob minha coordenação promoveu seminários, congressos, conferências, cursos, palestras, mesas-redondas e publicações. De destaque especial foram as iniciativas de promoção do I Seminário de Avaliação Institucional realizado em 1994 e publicação dos Anais do evento em 1995 e do Seminário dos 30 anos da Unicamp" em 1996 e publicação, resultante do evento, do livro: Escola e universidade na pós-modernidade, pela editora Mercado de Letras (2000).

No campo da pesquisa, publiquei dois trabalhos sobre núcleos ou grupos de pesquisas na Faculdade de Educação em 1982 e em 1987. Em 1982 via a existência de grupos de pesquisa como exceção à regra, quando até as agências de fomento à pesquisa privilegiavam os pesquisadores individuais. Em 1987 vislumbrava a tendência crescente para a formação de grupos de pesquisa. Publiquei vários outros trabalhos sobre pesquisa educacional, gestão educacional e educação superior, alguns individualmente, outros em equipe. No campo da formação de pesquisadores, fui orientador de mais de uma centena de mestres e doutores e participei de centenas de bancas de mestrado e de doutorado na UNICAMP e em várias universidades brasileiras.

\section{2) Entre outras atividades, você está vinculado ao Grupo de Pesquisa voltado ao Ensino Superior. O que motivou a criação de GEPES na Unicamp?}

Minha formação no doutorado com ênfase na educação superior, meus interesses de pesquisa na área, proposta de abertura de área de concentração em administração universitária elaborada por mim e implementada por mim e colaboradores externos em meu departamento em 1979 e desativada três anos depois por problemas de intrigas internas, a experiência de grupos de pesquisa e a existência de orientandos com 


\section{CIÊNCIAS HUMANAS}

REVISTA DO PROGRAMA DE PÓS-GRADUAĞ̈O EM EDUCAĞ̄o

\section{(1)URI|}

interesse na área foram os fatores motivadores da criação do GEPES que começou a funcionar informalmente em 1987 e foi aprovado formalmente em 1992, como já dissemos acima. Como complemento à criação do GEPES para viabilizar o mestrado e doutorado em educação com "área de concentração em educação superior", como tinha escrito num artigo sobre a educação superior como uma área de pesquisa, havia projetado mais três outras iniciativas que considerava relevantes para consolidar essa área de pesquisa na Faculdade: a criação de um centro de documentação sobre a educação superior brasileira, a criação de uma associação brasileira de educação superior (ABES) e a criação de uma revista de educação superior (RES). Das três, apenas a última pude concretizar, já como aposentado, e numa perspectiva mais ampla, mediante a colaboração de membros do GEPES. E assim foi criada a Revista Internacional de Educação Superior, em 2015. Graças à atuação dedicada da Profa. Dra. Maria de Lourdes de Almeida, membro do GEPES e docente da UNOESC, como Editora Associada, e à competência do Dr. Gildenir dos Santos, como Editor Técnicocientífico e especialista em biblioteconomia, a revista já conquistou em 2016 o Qualis B1 na avaliação dos periódicos pela Capes.

\section{3) O GEPES da Unicamp consolidou sua produção e ampliou seu espectro para GEPES nacional com sub-grupos de pesquisa, os quais potencializam a produção do campo. Como se deu este processo?}

Depois que me aposentei da Unicamp em 1999, a Profa. Dra. Elisabete Monteiro de Aguiar Pereira, minha ex-orientanda do doutorado, já contratada pela Faculdade de Educação, assumiu a coordenação do GEPES num momento quando já estava bastante consolidada a estruturação dos grupos de pesquisa na Faculdade. Depois da virada para o século XXI a Faculdade se reorganizou academicamente e a pós-graduação se estruturou em base aos grupos de pesquisa, estabelecendo a norma de seleção para o mestrado e o doutorado pelas linhas de pesquisa. Cada linha de pesquisa passou a ter uma cota de mestrandos e doutorandos, o que levou ao aumento de pós-graduandos vinculados ao GEPES e à produção de dissertações e teses na área da educação superior. Nesse período, embora já estivesse aposentado e afastado da UNICAMP até 2010, tive conhecimento da produção do GEPES. 


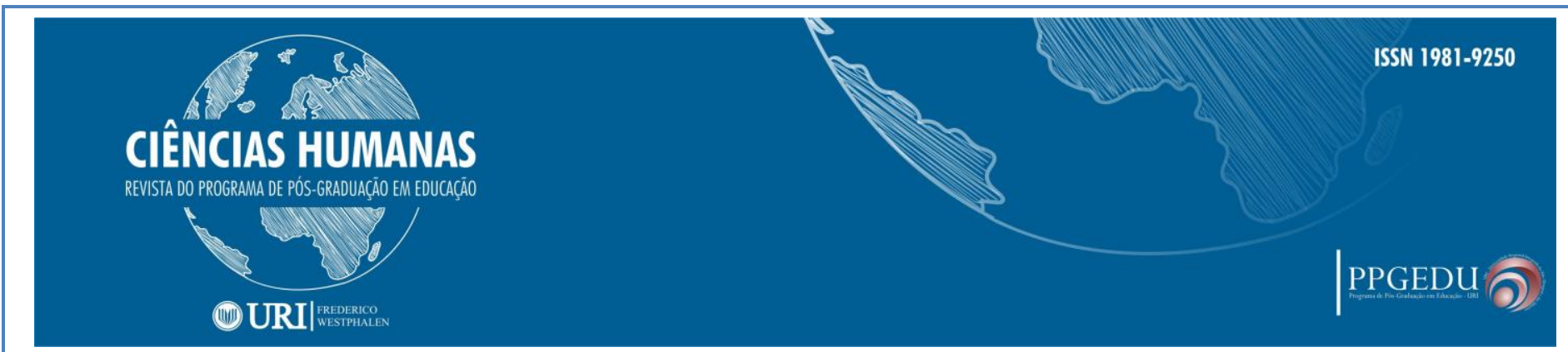

No retorno às suas respectivas universidades, alguns desses ex-pós-graduados, em consonância com a Profa. Elisabete, coordenadora do GEPES, criaram GEPES vinculados ao GEPES da Faculdade de Educação que passou a se redefinir como GEPES NACIONAL, articulador dos Gepes locais. Nesta fase, surgiram: o GEPESUNIVALI, GEPPES-UNOESC, GEPES-UNIOESTE, GEPES-UNIFAL Sob a coordenação do GEPES NACIONAL, esses grupos realizaram pesquisas sobre a educação superior brasileira e sobre a influência do processo de Bolonha nas universidades da América Latina, de modo especial na universidade brasileira.

\section{4) A exigência de internacionalização posta às Universidades, desafiou o GEPES a assumir uma dimensão internacional? Como se processou esta transição?}

Como já relatei em questões anteriores, primeiro, o GEPES se consolidou na Unicamp e participou da produção de pesquisa na área e colaborou na formação de mestres e doutores na área da educação superior. Depois, o GEPES cresceu no espaço nacional, especialmente em algumas universidades das Regiões Sudeste e Sul do país que criaram Gepes em seus programas de pós-graduação em educação, a partir de expós-graduados que fizeram doutorado na Faculdade de Educação da UNICAMP e que se integraram ao GEPES durante seus estudos na Unicamp. No momento, contatos internacionais, valorização da internacionalização da universidade, colaboração entre universidades brasileiras e universidades da América Latina, entre universidades latinoamericanas e universidades portuguesas e espanholas, colaboração internacional na publicação de capítulos de livros e artigos em revistas nacionais e contatos em eventos internacionais e em rede nacional dos gepinhos por estímulo e suporte da Capes, do CNPq e da Fapesp levaram o GEPES NACIONAL a se metamorfosear no GIEPES em outubro de 2015 para articular não só os GEPES já existentes vinculados ao da Faculdade de Educação da Unicamp, mas também outros grupos de pesquisa de educação superior criados em universidades brasileiras e em universidades da América Latina, de Portugal e da Espanha. Nessa nova fase, até o presente estão vinculados ao GIEPES, além dos GEPES já existentes, os novos seguintes: No Brasil: GEPESELOS/UFSM, GEPES-FURB, GEPES-SC/UFSC, GEPPES-SUL/UNOESC, GEPES- 


\section{CIÊNCIAS HUMANAS}

REVISTA DO PROGRAMA DE PÓS-GRADUAĞ̈O EM EDUCAĞ̄o

(10) URI/

UNICAMP, GEPES-UPF, GEPES-USP, NEPPES-URI; no exterior: IUSUR-Uruguai, PUC-Valparaíso/Chile, UNITREF/Argentina, UPNB-Bogotá/Colômbia， Univ. Aveiro/Portugal, Univ.Minho/Portugal, Univ. Granada/Espanha, Univ. Lusófona de Lisboa/Portugal.

\section{5) Avalie a posição do GIEPES no momento face às interações nacionais e internacionais.}

O GIEPES, no momento, coordena pesquisa sobre o conceito e as modalidades de internacionalização de universidades brasileiras, hispano-americanas, portuguesas e espanholas, tendo a participação de várias universidades brasileiras e de instituições ou universidades do Uruguai, da Argentina, do Chile, da Colômbia, da Venezuela, do México, de Portugal e da Espanha e até o presente recebeu "pasantias" de membros de Gepes do México e do Uruguai. Na realização desta pesquisa o GIEPES tem programado e realizado reuniões online com os participantes da pesquisa e já tem coletado dados preliminares sobre as instituições que aderiram ao projeto. No momento, com a participação das instituições envolvidas está começando a realizar as primeiras análises dos dados.

\section{6) Um marco importante do GIEPES foi a criação da Revista Internacional de Educação Superior. Como se deu esta iniciativa?}

A Revista Internacional de Educação Superior (RIESup) foi criada em 2015, antes da criação do GIEPES. Sua primeira vinculação foi com o GEPES NACIONAL. Com a transformação do GEPES NACIONAL no GIEPES, aquele foi extinto e, por isso, a RIESup passou a se vincular ao GIEPES a partir de 2018.

Minha proposta inicial era de criação de uma revista brasileira de educação superior, mas ao longo do processo de sua definição, o projeto se transformou numa revista internacional online. Integrada ao GIEPES, a revista acolhe artigos produzidos nos GEPES locais/regionais vinculados ao GIEPES e está aberta à publicação de pesquisas de grupos de pesquisa em educação superior do país e de outros países e não necessariamente apenas do espaço ibero-americano. Também por essa razão e para ampliar seu público-leitor acadêmico, a partir de 2018 a revista está implementando a 


\section{CIÊNCIAS HUMANAS}

REVISTA DO PROGRAMA DE PÓS-GRADUAĞ̈O EM EDUCAĞ̄o

\section{(1) URI|}

política de publicação bilíngue (português e inglês) num primeiro momento e mais adiante acrescentará também a publicação em espanhol. Como se trata de uma revista online, seu custo de produção editorial é menor do que a edição impressa.

7) Sabemos que não é fácil manter um periódico, respeitando os critérios da Capes, na perspectiva de melhorar os estratos avaliativos. Como você vê a situação dos periódicos no Brasil? Quais as maiores dificuldades?

O know-how de produção e administração dos periódicos no país aumentou rapidamente nessas duas primeiras décadas deste século, especialmente graças ao desenvolvimento das ferramentas computacionais e da tecnologia da informação que estão revolucionando os instrumentos de organização, divulgação e acesso à informação científica no mundo acadêmico. Além disso, as universidades brasileiras que estão consolidando as estruturas de suporte ao bom funcionamento da pós-graduação e da pesquisa estão aprimorando suas infraestruturas de bibliotecas e de edição de livros e periódicos, tornando mais profissional seu setor de edição e publicação de livros e periódicos, dimensão que confere muito prestígio às universidades. O tempo heroico e quase solitário de poucos docentes no envolvimento nesta atividade até o final do século XX já é história do passado. Agora já há a cultura de suporte institucional, tanto interno como externo à universidade, para assegurar a manutenção e continuidade da periodicidade dos periódicos. O conhecimento e a aplicação das regras burocráticas e formais de editoração dos periódicos já têm harmonizado o padrão dos periódicos no atendimento a esses critérios formais de qualidade editorial, mas vejo certo exagero desnecessário nas minúcias desses critérios. A qualidade acadêmica da contribuição de um trabalho científico passa pelo atendimento a critérios substantivos mais relevantes e indicativos dessa qualidade. Certo formalismo burocrático é necessário, mas não suficiente.

Mesmo reconhecendo esse avanço, há muitos aprimoramentos a serem buscados, como: a melhoria da infraestrutura interna de suporte administrativo, o aprimoramento dos critérios de avaliação, a facilitação e agilização de todo o processo de gestão do periódico mediante o suporte de aplicativos, a permanente atualização da capacidade gestora dos editores, a valorização do trabalho dos avaliadores dos artigos, a avaliação 


\section{CIÊNCIAS HUMANAS}

REVISTA DO PROGRAMA DE PÓS-GRADUAĞ̈O EM EDUCAĞ̄o

\section{(1) URI|}

da qualidade de cada periódico pelo menos por pares de avaliadores para assegurar maior credibilidade e fidedignidade ao resultado da avaliação classificadora do Qualis/Capes.

Por último, cabe reconhecer que administrar um periódico científico não se nasce sabendo. Por isso, a instituição que pretende embarcar nessa nova iniciativa acadêmica precisa valorizar, criar estrutura de apoio, alocar recurso e providenciar a capacitação do docente que manifestar interesse em investir parte de seu tempo de trabalho na universidade na criação e consolidação de um periódico científico de sua universidade. As universidades que assumirem o compromisso de publicação de periódicos precisam ter clareza que alocando recursos financeiros e humanos para administrar suas revistas, estão abrindo um canal de publicação mais para pesquisadores de outras universidades do que dos seus. Em contrapartida seus docentes irão publicar mais nos periódicos das outras universidades do que os delas. Ter periódicos confere prestígio às universidades, mas as que ainda não têm estrutura de pós-graduação, stricto sensu, consolidada deveriam concentrar recursos e esforços na sua consolidação e deixar para as universidades já consolidadas criar e administrar os periódicos científicos, considerando que os periódicos, para evitar a endogenia, constituem espaço de publicação mais para os pesquisadores de outras instituições do que dos seus.

8) Os Periódicos mais recentes encontram inúmeras dificuldades no processo de indexação em bases balizadas pela academia. Tais critérios são nacionais e não levam em conta o perfil das Universidades. Qual sua posição a respeito?

A ciência é internacional. Portanto os critérios de validade dos conhecimentos científicos devem ser de consenso internacional. Os critérios de avaliação da qualidade da ciência precisam ser rigorosos. É preciso também criar periódicos com foco mais aplicado a fim de traduzir a ciência teórica para contribuir para aprimorar a prática dos profissionais que colocam a "mão na massa". A divulgação da ciência no Brasil é um elo ainda precário no elo da publicação para os pares, publicação para os profissionais da prática e divulgação para o público mais amplo a fim de elevar seu nível cultural. A publicação para esses dois últimos tipos de públicos precisa adotar critérios de avaliação diferentes. Essa sugestão vale para todas as áreas do conhecimento. No Brasil, 


\section{CIÊNCIAS HUMANAS}

REVISTA DO PROGRAMA DE PÓS-GRADUAĞ̈O EM EDUCAĞ̄o

\section{(1) URI|}

carecemos de publicação para esses dois tipos dos elos da publicação e divulgação científica. A publicação também em inglês é importante para os periódicos de perfil mais acadêmico e de excelência para tornar a ciência brasileira conhecida pelos nossos pares internacionais, o que contribuirá para dar visibilidade e importância à produção de excelência do país.

9) Prof. Camilo parece-nos que são tempos duros para os estudos de Políticas Educacionais. Como pesquisador do campo de Políticas Educacionais, em sua experiência, como percebe a atual conjuntura da Universidade no território iberoamericano?

Vejo a consolidação da pós-graduação e da pesquisa universitária no Brasil, no Chile e no México. Não tenho muita clareza do avanço da Argentina, Colômbia e Venezuela na consolidação dessa estrutura. Portugal e Espanha, com a política de ajuste ao processo de Bolonha, certamente vêm avançando na consolidação de sua estrutura de pós-graduação e pesquisa para se aproximarem dos padrões da França, Alemanha e Inglaterra.

Na pós-graduação brasileira, observadores externos, como Cláudio Rama, pesquisador do Uruguai e com larga experiência em universidades latino-americanas, veem excesso de regulamentação, quando o ambiente favorável à pós-graduação, à pesquisa e à criatividade é a flexibilidade, a liberdade, o mínimo de regras burocráticas. Além desse problema, no momento devido à crise econômica e política do país, os avanços na pós-graduação e na pesquisa brasileira sofrem o risco de paralisia e até mesmo de desmonte de algumas linhas de pesquisa por falta de verbas de fomento, bolsas de estudo e de contratação de pesquisadores pelas universidades. Em cinquenta anos de história de sua pós-graduação, a universidade americana já tinha formado alguns pesquisadores que ganharam prêmio Nobel. Em cinquenta anos de história, que relevância tem nossa pós-graduação no desenvolvimento da ciência atual e do país? Nosso produtivismo acadêmico está enchendo as prateleiras físicas ou virtuais de nossas bibliotecas físicas ou virtuais para conseguir boa avaliação da Capes e ascender na carreira acadêmica ou para avançar as fronteiras do conhecimento humano e desenvolver o país? 


\section{CIÊNCIAS HUMANAS}

REVISTA DO PROGRAMA DE PÓS-GRADUAĞ̈O EM EDUCAĞ̄o

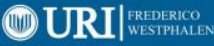

Enquanto o Brasil lidera a consolidação da pós-graduação na América Latina, a Argentina e alguns outros países hispanos lideram na qualidade da Graduação em suas universidades públicas que formam a maioria dos estudantes de graduação. A situação brasileira nesse nível de ensino talvez seja a mais precária, dada a predominância das universidades e faculdades particulares comerciais no nosso ensino de graduação. A democratização da educação superior por essa via será um engodo de inclusão social pela educação. Há necessidade de o Estado brasileiro de preferência diversificar o sistema de educação superior pela via pública para efetivamente aprofundar a democratização do nível de graduação. A via privada, com as devidas exceções, é comércio precário da educação superior para fins técnicos e pouco formativos. A inclusão e incorporação das "minorias" pela via das universidades/faculdades/facilidades particulares é mera ilusão de democratização da educação superior e um grande negócio para seus donos. Nesse aspecto, ou seja, no nível da graduação, o Brasil possivelmente esteja na situação mais precária da América Latina. Para o bem do país, o Estado deveria privilegiar e priorizar as instituições públicas de educação superior e as instituições privadas de educação superior efetivamente sem fins lucrativos, do contrário nunca teremos sequer um arremedo de Harvard, MIT, Chicago ou Stanford.

Finalmente, vejo a necessidade de nossas universidades públicas profissionalizarem a gestão universitária para otimizar sua eficiência administrativa e ampliarem sua internacionalização para avançar na melhoria da qualidade acadêmica, atrair mestres e estudantes estrangeiros, conquistar o status de excelência acadêmica.

10) Para encerrar nossa entrevista, gostaríamos de saber quais foram os maiores obstáculos enfrentados por você no papel de pesquisador e de editor, já que foi um dos fundadores do caderno CEDES da UNICAMP. Poderia destacar os pontos positivos advindos destes dois papeis durante todos esses anos do seu trabalho acadêmico?

$\mathrm{Na}$ resposta à primeira pergunta e às demais já destaquei algumas dimensões positivas e negativas que encontrei em minha instituição e ao longo de minha trajetória como pesquisador e editor de periódicos científicos. Para ser breve nessa resposta, já que fui prolixo nas anteriores, vou citar apenas alguns pontos positivos e negativos que 


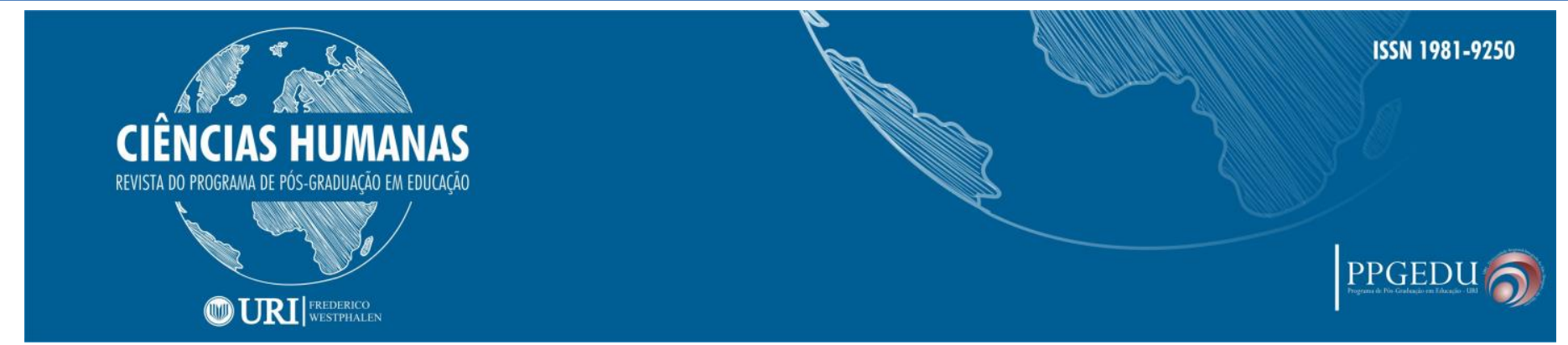

destacaria pelo impacto na criação de condições de trabalho que afetam o trabalho do professor-pesquisador da UNICAMP. Entre os positivos, citaria, entre outros: a valorização da pesquisa pela universidade, a vinculação da produção de pesquisa à progressão na carreira, o suporte quase ilimitado para enriquecer as bibliotecas da Universidade com periódicos e livros como suporte à pesquisa [isso nos anos dourados da Unicamp], o estímulo ao trabalho em equipe na fase de criação dos grupos de pesquisa, a facilidade e o suporte financeiro para participação em eventos científicos no país e no exterior, o ambiente de trabalho [falo do meu tempo na ativa] razoavelmente sadio.

Entre os pontos negativos, entre outros, destacaria: o crescente processo de burocratização da universidade, a falta de planejamento estratégico da universidade, o excesso de reuniões burocráticas mais do que acadêmicas, a sobrecarga de tarefas administrativas para os docentes doutores de dedicação exclusiva em razão de constituírem uma minoria dos membros do departamento (isso nos anos setenta e oitenta), a seleção de colegas de trabalho mais pela afinidade ideológica do que pela competência acadêmica, a interferência negativa da política partidária na administração da universidade, a falta de suporte técnico, administrativo e financeiro para produzir e administrar a revista da Faculdade, especialmente depois da gestão da revista pela Editora Cortez (isso nos anos heroicos da revista).

Agradecemos sua atenção e generosidade.

Obrigada.

Profa. Edite Maria Sudbrack 